\title{
TNF- $\alpha$ and IL-1 $\beta$-activated human mesenchymal stromal cells increase airway epithelial wound healing in vitro via activation of the epidermal growth factor receptor
}

Winifred Broekman ${ }^{1 *}$, Gimano D. Amatngalim, Yvonne de Mooij-Eijk1, Jaap Oostendorp², Helene Roelofs ${ }^{3}$, Christian Taube ${ }^{1}$, Jan Stolk ${ }^{1}$ and Pieter S. Hiemstra ${ }^{1}$

\begin{abstract}
Background: Mesenchymal stromal cells (MSCs) are investigated for their potential to reduce inflammation and to repair damaged tissue. Inflammation and tissue damage are hallmarks of chronic obstructive pulmonary disease (COPD) and MSC infusion is a promising new treatment for COPD. Inflammatory mediators attract MSCs to sites of inflammation and affect their immune-modulatory properties, but little is known about their effect on regenerative properties of MSCs. This study investigates the effect of the pro-inflammatory cytokines TNF- $\alpha$ and IL-1 $\beta$ on the regenerative potential of MSCs, using an in vitro wound healing model of airway epithelial cells.

Methods: Standardized circular wounds were created by scraping cultures of the airway epithelial cell line NClH292 and primary bronchial epithelial cells cultured at the air-liquid interface (ALI-PBEC), and subsequently incubated with MSC conditioned medium (MSC-CM) that was generated in presence or absence of TNF-a/IL-1 $\beta$. Remaining wound size was measured up to $72 \mathrm{~h}$. Phosphorylation of ERK $1 / 2$ by MSC-CM was assessed using Western blot. Inhibitors for EGFR and c-Met signaling were used to investigate the contribution of these receptors to wound closure and to ERK1/2 phosphorylation. Transactivation of EGFR by MSC-CM was investigated using a TACE inhibitor, and RT-PCR was used to quantify mRNA expression of several growth factors in MSCs and NCI-H292.

Results: Stimulation of MSCs with the pro-inflammatory cytokines TNF- $a$ and IL-1 $\beta$ increased the mRNA expression of various growth factors by MCSs and enhanced the regenerative potential of MSCs in an in vitro model of airway epithelial injury using NCl-H292 airway epithelial cells. Conditioned medium from cytokine stimulated MSCs induced ERK1/2 phosphorylation in NCI-H292, predominantly via EGFR; it induced ADAM-mediated transactivation of EGFR, and it induced airway epithelial expression of several EGFR ligands. The contribution of activation of c-Met via HGF to increased repair could not be confirmed by inhibitor experiments.

Conclusion: Our data imply that at sites of tissue damage, when inflammatory mediators are present, for example in lungs of COPD patients, MSCs become more potent inducers of repair, in addition to their well-known immunemodulatory properties.
\end{abstract}

Keywords: Lung, Chronic obstructive pulmonary disease, Inflammation, Airway epithelial cells, NCI-H292, Mesenchymal stromal cells, Wound healing, Regeneration, Repair, TNF-a/IL-1ß

\footnotetext{
* Correspondence: w.broekman@lumc.nl

${ }^{1}$ Department of Pulmonology, Leiden University Medical Center, Albinusdreef

2, 2333 ZA Leiden, The Netherlands

Full list of author information is available at the end of the article
} 


\section{Background}

In chronic obstructive pulmonary disease (COPD), the release of proteases and other mediators by a variety of inflammatory and resident cells is thought to cause tissue damage within the lung [1-3]. The endogenous regenerative capacity of the lung to restore damaged structures is limited, and the resulting imbalance between insufficient repair mechanisms and excess tissue damage will lead to irreversible tissue damage [4], ultimately causing organ failure.

Current COPD treatment targets symptoms, and there is a lack of treatments that halt disease progression and/ or restore lung structure. The only current option for patients with chronic respiratory failure due to severe emphysema is lung transplantation, but the availability of donor lungs is limited and the success of lung transplantation varies. Therefore, new approaches to restore damaged lung tissue in COPD are needed.

A promising therapeutic approach that targets restoration of destructed lung tissue as well as reduction of inflammation is the administration of mesenchymal stromal cells (MSCs). MSCs are multipotent progenitor cells of non-hematopoietic origin defined by their capacity to differentiate into multiple lineages of the mesenchyme [5]. Besides their differentiation capacity, MSCs can favour repair of wounded tissue by modulating cellular responses in structural and immune cells, creating a regenerative and anti-inflammatory environment (reviewed in $[6,7])$. The main mechanisms by which MSCs exert these effects are via cell-cell interactions and secretion of soluble factors.

Indeed, MSCs can reduce inflammation and repair alveolar structures as has been demonstrated in in vivo rodent models of cigarette smoke or elastase-induced emphysema [8-10]. It has been suggested that MSCs mediate this effect in part via the release of soluble factors, including hepatocyte growth factor (HGF) and epidermal growth factor receptor (EGFR) ligands, which can both increase proliferation of epithelial cells [11-15]. The receptors for these growth factors, c-Met and EGFR respectively, can activate extracellular signal-regulated kinase $1 / 2($ ERK1/2), one of the mitogen activated protein kinases (MAPK). Activation of this signaling pathway results in proliferation, differentiation and migration, processes that are fundamental for wound repair [16]. Whereas conditioned medium from MSCs has been shown to enhance airway epithelial wound healing in vitro [17], the contribution of HGF or EGFR ligands and underlying ERK1/2 signaling has not yet been investigated.

Another interesting and yet unanswered issue is whether pro-inflammatory cytokines can affect the potential of bone-marrow derived MSCs to repair damaged pulmonary epithelium at sites of inflammation. It is known that inflammatory mediators can attract MSCs (reviewed in $[18,19])$ and alter their secretome [20-24], which is beneficial for the immune response [22] and for skin wound healing [25]. However, whether inflammatory mediators also increase the potential of bone marrowderived MSCs to repair damaged pulmonary epithelium remains to be elucidated. Moreover, the cellular and molecular mechanisms that underlie such a repair potentiating effect within the airway epithelium are largely unknown.

Therefore, in the present study we investigated the effect of pro-inflammatory cytokines involved in the pathogenesis of COPD (i.e. Tumour Necrosis Factor- $\alpha$ $($ TNF- $\alpha$ ) and Interleukin-1 $\beta$ (IL-1 $\beta))[26-29]$ on the expression of growth factors by MSCs. We explored the effect of the conditioned medium from these stimulated MSCs on airway epithelial wound repair in vitro, and the contribution of the ERK1/2 signaling pathway, c-Met and EGFR to this effect. Our results show that stimulation of MSCs with TNF- $\alpha$ and IL- $1 \beta$ increases their regenerative potential as assessed in an in vitro model of airway epithelial repair. Furthermore, we demonstrate the crucial involvement of EGFR-activation in this process.

\section{Methods}

\section{Cell culture}

Cells from the NCI-H292 human lung mucoepidermoid carcinoma epithelial cell line (American Type Culture Collection, Manassas, VA, USA) were cultured in RPMI 1640 (Gibco, Grand Island, NY, USA), supplemented with $100 \mathrm{U} / \mathrm{ml}$ penicillin, $100 \mu \mathrm{g} / \mathrm{ml}$ streptomycin and $2 \mathrm{mM}$ glutamine (all from Bio Whittaker, Walkersville, MD, USA) and $10 \%[\mathrm{v} / \mathrm{v}]$ heat inactivated fetal calf serum (FCS) (Bodinco, Alkmaar, The Netherlands). Human primary bronchial epithelial cells (PBEC) isolated from tumour-free bronchial tissue [30] were cultured on semipermeable transwell membranes with a $0.4 \mu \mathrm{m}$ pore size (Corning Costar, Cambridge, MA, USA). Transwells were coated with $30 \mu \mathrm{g} / \mathrm{ml}$ PureCol (Advanced BioMatrix, San Diego, CA, USA), $10 \mu \mathrm{g} / \mathrm{ml}$ bovine serum albumin (BSA) (Sigma-Aldrich, St. Louis, MO, USA) and $10 \mu \mathrm{g} / \mathrm{ml}$ fibronectin diluted in PBS. Upon establishment of a confluent cell layer, PBEC were cultured at the air-liquid interface (ALI) during 2 weeks for differentiation. Culture medium consisted of a 1:1 mixture of bronchial epithelial growth medium (BEGM) (Lonza, Verviers, Belgium) and Dulbecco's modified Eagle's medium (DMEM) (Gibco), supplemented with $0.4 \%(\mathrm{w} / \mathrm{v})$ bovine pituitary extract (BPE), $1 \mu \mathrm{M}$ hydrocortisone (HC), $0.5 \mathrm{ng} / \mathrm{ml}$ human epidermal growth factor (hEGF), $0.5 \mu \mathrm{g} / \mathrm{ml}$ epinephrine, $10 \mu / \mathrm{ml}$ transferrin, $5 \mu \mathrm{g} / \mathrm{ml}$ insulin, T3, $0.1 \mathrm{ng} / \mathrm{ml}$ retinoic acid (RA), $1 \mathrm{mM}$ Hepes (all Lonza), $1 \mathrm{mg} / \mathrm{ml}$ BSA (SigmaAldrich), $100 \mathrm{U} / \mathrm{ml}$ penicillin and $100 \mu \mathrm{g} / \mathrm{ml}$ streptomycin (Lonza), and additional supplementation of $15 \mathrm{ng} / \mathrm{ml} \mathrm{RA}$ (Sigma-Aldrich) for mucociliary differentiation. 
Mesenchymal stromal cells (MSCs) were isolated from bone marrow from healthy donors and expanded in culture following a previously described protocol of the department of Immunohaematology and Blood Transfusion at Leiden University Medical Center [31]. MSC characterization was based on morphology and immunophenotyping using flow cytometry for the following markers: HLA-DR, CD73, CD90, CD31, CD34, CD45, CD80 (Becton Dickinson (BD) Bioscience, Franklin Lakes, NJ, USA) and CD105 (Ancell, Bayport, MN, USA), using FACSCalibur and CellQuest Pro Software (BD Bioscience). MSCs were cultured in DMEM GlutaMAX ${ }^{\text {ma }}$ (Gibco), supplemented with $100 \mathrm{U} / \mathrm{ml}$ penicillin and $100 \mu \mathrm{g} / \mathrm{ml}$ streptomycin, and $10 \%[\mathrm{v} / \mathrm{v}]$ heat-inactivated FCS (Thermo Fisher Scientific, UT, USA). All cells were cultured at $37{ }^{\circ} \mathrm{C}$ in a $5 \% \mathrm{CO}_{2}$ humidified incubator. Before experiments, NCI-H292 and MSCs were starved for growth factors overnight using serum-free (SF) culture medium; ALI-PBEC were starved for growth factors in B/ D medium lacking BPE, HC, hEGF, RA and BSA. Prior to experiments, the apical side of ALI-PBEC cultures was washed with $100 \mu \mathrm{L}$ of PBS to remove excess mucus.

\section{Preparation of conditioned medium}

MSCs were grown until 80-90\% confluence and starved overnight in serum-free medium after washing with PBS. To generate MSC conditioned medium (MSC-CM), cells were cultured for $24 \mathrm{~h}$ in either serum-free medium (LG-DMEM) containing TNF- $\alpha$ and IL-1 $\beta$ (both $20 \mathrm{ng} /$ ml; Peprotech, Rocky Hill, NJ, USA) (to generate MSC$\mathrm{CM}^{\mathrm{STIM}}$ ) or serum-free medium alone (to generate

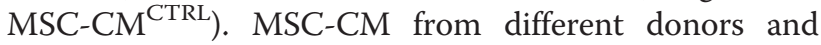
generated at different passages was pooled before experiments to reduce effects caused by donor and/or passage variation. All wound healing experiments were performed with MSC-CM at passage 4-6. A part of the western blot experiments were performed with MSC$\mathrm{CM}$ at passage 2-4. Control DMEM medium with TNF$\alpha$ and IL-1 $\beta$ (DMEM ${ }^{\text {STIM }}$ ) or without $\left(\right.$ DMEM $\left.^{\text {CTRL }}\right)$ was obtained by incubating medium in culture flasks not containing cells in the same incubator for $24 \mathrm{~h}$. MSC$\mathrm{CM}$ and DMEM control medium were harvested and centrifuged for $7 \mathrm{~min}$ at $230 \mathrm{xg}$ to remove debris, and stored in $2 \mathrm{ml}$ aliquots at $-80{ }^{\circ} \mathrm{C}$ until further use.

\section{Wound repair model}

A confluent monolayer of NCI-H292 cells or differentiated ALI-PBEC was mechanically injured by scraping the cell layer with a sterile Pasteur pipette with a soft tip (essentially as described in [32]). Two wounds with a diameter of $3 \mathrm{~mm}$ each were made in each well in a 12 wells plate for NCI-H292, or one wound per Transwell insert for ALI-PBEC. Each experiment was performed in duplicate. After wounding, medium was replaced by the following stimuli: serum free standard culture medium (negative control); $20 \mathrm{ng} / \mathrm{ml}$ Transforming Growth Factor- $\alpha$ (TGF- $\alpha$ ) (Sigma-Aldrich, St. Louis, MO, USA) in serum free standard culture medium (positive control [32]); or MSC-CM and the corresponding DMEM controls, which were all diluted 1:2 in serum free standard culture medium (based on dose response experiments), unless otherwise specified. For inhibitor experiments exploring the role of c-Met and the Epidermal Growth Factor receptor (EGFR) in wound healing, $0.05 \mu \mathrm{M}$ PF04217903 (c-Met inhibitor; Sigma-Aldrich) and/or $0.2 \mu \mathrm{M}$ AG1478 (EGFR tyrosine kinase inhibitor; Calbiochem, Darmstadt, Germany) were added to relevant stimuli for the full culturing period. Hepatocyte Growth Factor (HGF) (Peprotech) and TGF- $\alpha$ (both at $20 \mathrm{ng} / \mathrm{ml}$ in LG-DMEM) served as positive controls, whereas LGDMEM was used as negative control (DMEM $\left.{ }^{\mathrm{CTRL}}\right)$.

Digital images of the wounds were collected every $24 \mathrm{~h}$ up to $72 \mathrm{~h}$ maximum (NCI-H292) or at 6, 24 and $48 \mathrm{~h}$ (ALI-PBEC), on an inverted phase-contrast light microscope using Cell Sense Entry imaging software (both from Olympus, Tokyo, Japan). The surface of the wound area was measured using Image $J$ software (National Institutes of Health, USA), and residual wound area in percentage was assessed by comparing the remaining wound size at different time points with the wound size at the start of the experiment ( $(1$-wound size $\mathrm{t}=\mathrm{x}$ /wound size $\mathrm{t}=0) * 100$ ).

\section{Phosphorylation of ERK $1 / 2$}

NCI-H292 cells used for assessment of ERK1/2 phosphorylation were cultured to $70 \%$ confluence in a 12 wells plate. All stimuli were diluted 1:2 in RPMI. Cells were stimulated with either MSC-CM ${ }^{\text {STIM }}$ or DMEM $^{\text {STIM }}$. HGF or TGF- $\alpha$ in a final concentration of $20 \mathrm{ng} / \mathrm{ml} \mathrm{di-}$ luted in LG-DMEM and DMEM ${ }^{\mathrm{CTRL}}$ were used as positive resp. negative controls.

The role of c-Met and EGFR activation was investigated by pre-incubation of cells during $1 \mathrm{~h}$ with either $0.05 \mu \mathrm{M}$ PF04217903, or $10 \mu \mathrm{M}$ AG1478, or $2 \mu \mathrm{g} / \mathrm{ml}$ neutralizing antibodies against EGFR (Calbiochem) dissolved in RPMI in assigned wells before addition of stimuli. The role of transactivation was evaluated using the TNF- $\alpha$ converting enzyme (TACE)/ADAM17 inhibitor TAPI-1 $(10 \mu \mathrm{M})$ (Santa Cruz Biotechnology, Dallas, TX, USA). Controls were treated with an equal volume of RPMI for $1 \mathrm{~h}$.

Cells were incubated with stimuli for 15 min or various time periods for time-series experiments, and immediately cooled down on ice and washed with cold ERK washing buffer (5 mM Tris $\mathrm{pH} 7.4,100 \mathrm{mM} \mathrm{NaCl}$, $1 \mathrm{mM} \mathrm{CaCl}_{2}, 1 \mathrm{mM} \mathrm{MgCl}$ ). Cell lysates were generated by incubation with lysis buffer $(0.5 \%$ [v/v] Triton X-100, $1 \mathrm{mM} \mathrm{Na} \mathrm{NO}_{4}$ and Mini complete protease cocktail 
(Roche, Basel, Switzerland) in ERK washing buffer) for $15 \mathrm{~min}$. Samples from duplicate wells were pooled. After dilution in 2 times concentrated reducing sample buffer (4 \% [v/v] SDS, $10 \%$ [v/v] beta-Mercaptoethanol, $20 \%$ [v/ v] glycerol, $0.5 \mathrm{M}$ Tris pH 6.8 and $0.003 \%$ [w/v] Bromphenol blue) samples were boiled for 5 min and spun down at 20780xG for $5 \mathrm{~min}$, before loading and running on a $10 \%$ SDS-PAGE gel. Proteins were transferred onto a polyvinylidene difluoride membrane using the Mini-transblot system (both from Bio-Rad, Hercules, CA, USA).

Non-specific binding sites on the blots were blocked with PBS/0.05 \% [v/v] Tween 20/0.5 \% [w/v] casein (Sigma-Aldrich) for at least one hour followed by overnight incubation at $4{ }^{\circ} \mathrm{C}$ with antibodies directed against total and phospho-ERK1/2 (Cell Signaling, Beverly, MA, USA) in PBS/0.05\% Tween 20. After washing of the blot with PBS/0.05 \% Tween 20, secondary HRP labeled goat antibodies (BD Bioscience) were added for $1 \mathrm{~h}$ at room temperature, followed by extensive washing. The membranes were developed on film (FujiFilm Corporation, Tokyo, Japan) using enhanced chemiluminescent (ECL) detection system (ThermoScientific, Rockford, IL, USA).

\section{mRNA expression}

NCI-H292 cells were grown to near confluence and exposed to MSC-CM ${ }^{\text {STIM }}$ or DMEM $^{\text {STIM }}$ or DMEM ${ }^{\text {CTRL }}$ (neg ctrl) 1:2 in RPMI. MSCs were grown to $80-90 \%$ confluence and stimulated with TNF- $\alpha$ and IL- $1 \beta(20 \mathrm{ng} / \mathrm{ml}$ each) or serum free medium. Incubation times were based on initial experiments on limited samples revealing the largest increase of mRNA expression for several genes after $9 \mathrm{~h}$ (NCI-H292) and $6 \mathrm{~h}$ (MSCs) of stimulation. Sample triplicates from a 24 wells plate were pooled and RNA was extracted using Maxwell ${ }^{\circ} 16$ RNA Purification Kit (Promega, Madison, WI, USA) according to the manufacturers protocol, and quantified using the Nanodrop ND-1000 UV-visible spectrophotometer (Nanodrop Technologies, Wilmington, DE, USA). Complementary DNA was generated by adding Oligo(dT) primers (Qiagen, Düsseldorf, Germany) and $10 \mathrm{nM}$ dNTP mix (Promega) to the RNA sample, and heating this to $65^{\circ} \mathrm{C}$ for 5 min. Subsequently, 5x 1st strand RNA buffer, RNasin and M-MLV (all from Promega) were added, and the samples were incubated at $37^{\circ} \mathrm{C}$ during $50 \mathrm{~min}$ followed by heat inactivation of M-MLV at $70{ }^{\circ} \mathrm{C}$ during $15 \mathrm{~min}$. Primers were designed using PubMed Gene Database and Primerbank (http://pga.mgh.harvard.edu/primerbank) (Table 1) (Invitrogen, Thermo Fisher Scientific, Waltham, MA, USA). Quantitative real-time PCR was performed in triplicate in a 384 wells plate (Bio-Rad CFX384 ${ }^{\mathrm{max}}$ ), with samples mixed with respective primers and SYBR Green supermix (Bio-Rad) in a final volume of $8 \mu \mathrm{l}$. Results were checked for outliers: outliers were removed if the variance within triplicates was above $10 \%$.

Expression of $A C T B$ and GAPDH was used to normalize mRNA expression in MSCs, whereas RPL13A and $A T P 5 B$ were used for NCI-H292 (Table 1).

\section{Statistics}

The data are expressed as mean \pm standard error of the mean unless depicted otherwise. GraphPad Prism 6.0 (GraphPad Inc., La Jolla, CA, USA) was used for statistical analysis. For comparison between groups, the Mann-Whitney test was used, for comparison of three or more groups the Kruskall Wallis test. Differences were considered significant when $p<0.05$.

Table 1 Primers for RT-PCR

\begin{tabular}{|c|c|c|}
\hline GENE & Primer sequence FW & Primer sequence RV \\
\hline ACTB & TTC CAG GAG CGA GAT CCC T & CAC CCA TGA CGA ACA TGG G \\
\hline ATP5B & TCA CCC AGG CTG GTT CAG A & AGT GGC CAG GGT AGG CTG AT \\
\hline GAPDH & TTC CAG GAG CGA GAT CCC T & CAC CCA TGA CGA ACA TGG G \\
\hline RPL13A & AAG GTG GTG GTC GTA CGC TGT G & CGG GAA GGG TTG GTG TTC ATC C \\
\hline AREG & GGT GGT GCT GTC GCT CTT G & AGG TGT CAT TGA GGT CCA ATC C \\
\hline CCDN1 & CAA TGA CCC CGC ACG ATT TC & CAT GGA GGG CGG ATT GGA A \\
\hline EGF & TGC AGA GGG ATA CGC CCT AA & CAA GAG TAC AGC CAT GAT TCC AAA \\
\hline FGF2 & TGG CTA TGA AGG AAG ATG GAA GA & TCC AAT CGT TCA AAA AAG AAA CAC \\
\hline$H B-E G F$ & TGG ACC TTT TGA GAG TCA CTT TAT CC & CGT GCT CCT CCT TGT TTG GT \\
\hline HGF & TCC AGA GGT ACG CTA CGA AGT CT & CCC ATT GCA GGT CAT GCA T \\
\hline IL6 & CAG AGC TGT GCA GAT GAG TAC A & GAT GAG TTG TCA TGT CCT GCA G \\
\hline PDGFA & CAC CAC CGC AGC GTC AA & CCT CAC CTG GAC TTC TाT TAA TTT TG \\
\hline TGFA & AGG TCC GAA AAC ACT GTG AGT & AGC AAG CGG TTC TTC CCT TC \\
\hline VEGF & CGA GGG CCT GGA GTG TGT & TGG TGA GGT TTG ATC CGC ATA \\
\hline
\end{tabular}




\section{Results}

Stimulation of MSCs with pro-inflammatory cytokines induces mRNA expression of several growth factors and leads to increased protein levels of HGF

To investigate the effect of pro-inflammatory cytokines on growth factor expression in MSCs, the mRNA expression of a variety of growth factors was analyzed in MSCs stimulated with TNF- $\alpha$ and IL-1 $\beta$ (20 ng/ml each).

The mRNA expression of the growth factors Fibroblast Growth Factor 2 (FGF2), Hepatocyte Growth Factor $(H G F)$, Heparin-binding EGF-like growth factor (HBEGF) and Interleukin-6 (IL6) was significantly increased $(p<$ $0.05)$, and a non-significant increase was observed in amphiregulin (AREG) $(p=0.06)$. mRNA expression of the other growth factors evaluated did not change significantly (Fig. 1).

\section{MSC conditioned medium increases wound closure in $\mathrm{NCl}-\mathrm{H} 292$ monolayers}

Exposure of MSCs to the pro-inflammatory cytokines TNF- $\alpha$ and IL- $1 \beta$ resulted in increased mRNA expression of several growth factors. To assess whether this observation has functional relevance, a wound closure model was used to investigate the effect of MSC-CM ${ }^{\text {STIM }}$ on wound closure in NCI-H292 airway epithelial cell monolayers.

No significant differences were observed when wounded NCI-H292 cells were incubated with conditioned medium from unstimulated MSCs (MSC-CM ${ }^{\mathrm{CTRL}}$ ), compared to the control medium (DMEM ${ }^{\mathrm{CTRL}}$ ) (Fig. 2a). In contrast, MSC-CM from TNF- $\alpha$ and IL- $1 \beta$ stimulated MSCs (MSC-CM ${ }^{\text {STIM }}$ ) significantly enhanced wound closure compared to DMEM ${ }^{\text {STIM }}$ (also containing TNF- $\alpha$ and IL$1 \beta$ ) after 24 and $48 \mathrm{~h}$ and was even more effective than the positive control TGF- $\alpha$ (Fig. 2b, c) ( $p=0.002$ at $48 \mathrm{~h}$ ). The effect of MSC-CM ${ }^{\text {STIM }}$ was dose-dependent and still detectable at a 1:10 dilution (Fig. 2d).

Next the effect of MSC-CM on wound closure in welldifferentiated cultures of ALI-PBEC was investigated. Wound closure in ALI-PBEC cultures was faster than in NCI-H292, and full wound closure was observed within 48 h. In ALI-PBEC, MSC-CM ${ }^{\text {STIM }}$ also significantly increased epithelial wound closure, however to a similar extent as its control (DMEM ${ }^{\text {STIM }}$ ) (Fig. 2e, f).

\section{MSC-CM ${ }^{\text {STIM }}$ activates ERK1/2 signaling in $\mathrm{NCl}-\mathrm{H} 292$} monolayers via (trans)activation of the EGF-receptor The observation that MSC-CM ${ }^{\text {STIM }}$ enhanced wound closure in NCI-H292 monolayers prompted further investigation into the underlying cellular response accountable for this effect. Epithelial wound healing is regulated by activation of mitogen activated protein kinases (MAPKs), and in particular via activation of the MAPK Extracellular signal-Regulated Kinase (ERK)1/2, which is known to be involved in cell proliferation, differentiation and migration [16, 33]. Therefore we further examined the role of this pathway in MSC-CM induced wound healing.

In NCI-H292 monolayers, MSC-CM ${ }^{\text {STIM }}$ increased ERK1/2 phosphorylation, when compared to DMEM ${ }^{\text {STIM }}$ (Fig. 3a, b). This effect was more pronounced at early time points (15-30 min), but could be observed up to $6 \mathrm{~h}$ of stimulation (Fig. 3c, d).
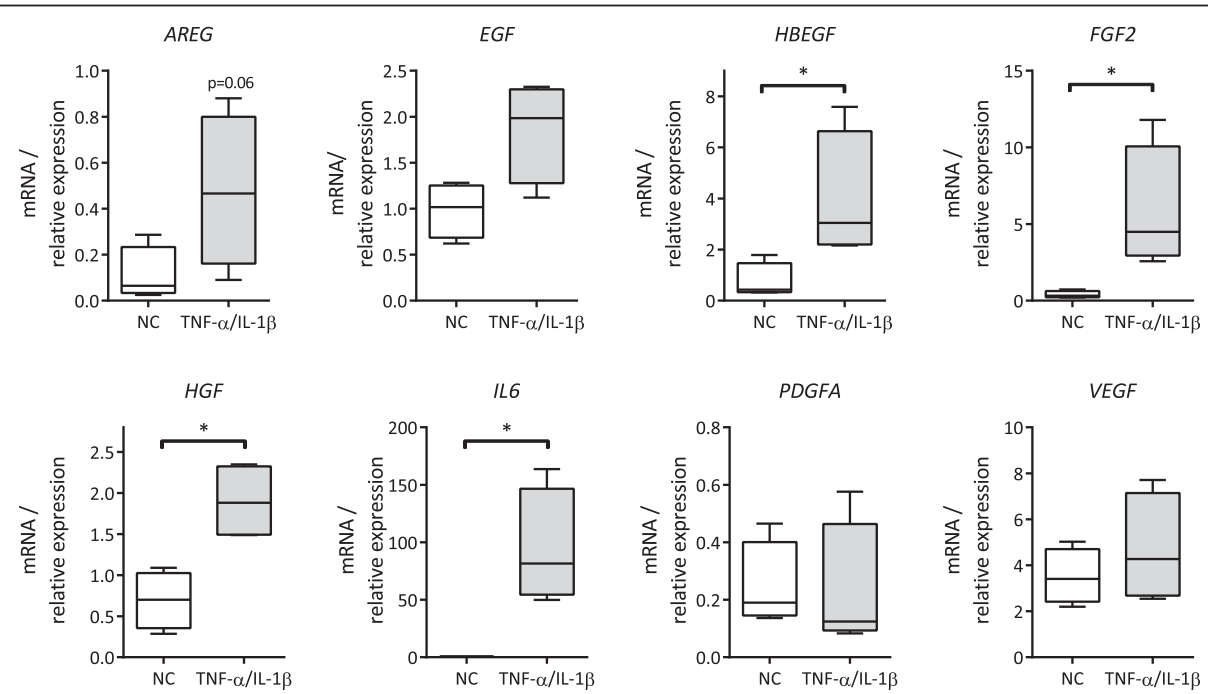

Fig. 1 Stimulation of MSCS with TNF- $\alpha$ and IL-1 $\beta$ increases the expression of several growth factors. MSCs were stimulated with TNF- $a$ and IL-1 $\beta$ $20 \mathrm{ng} / \mathrm{ml}$ each and harvested for RNA extraction after $6 \mathrm{~h}$. mRNA expression of various growth factors (AREG, EGF, HBEGF (all EGFR ligands), FGF2, $H G F, I L 6, P D G F A$, and VEGF) was determined by qPCR, which showed a significant increase of FGF2, HBEGF, HGF and of IL6, and an increase of AREG and EGF. Values were normalized to $A C T B$ and GAPDH reference genes. Box and whiskers represent median, interquartile range and minimum and maximum for $n=4$ obtained from three different donors; $\left(^{*}\right) p<0.05$ 

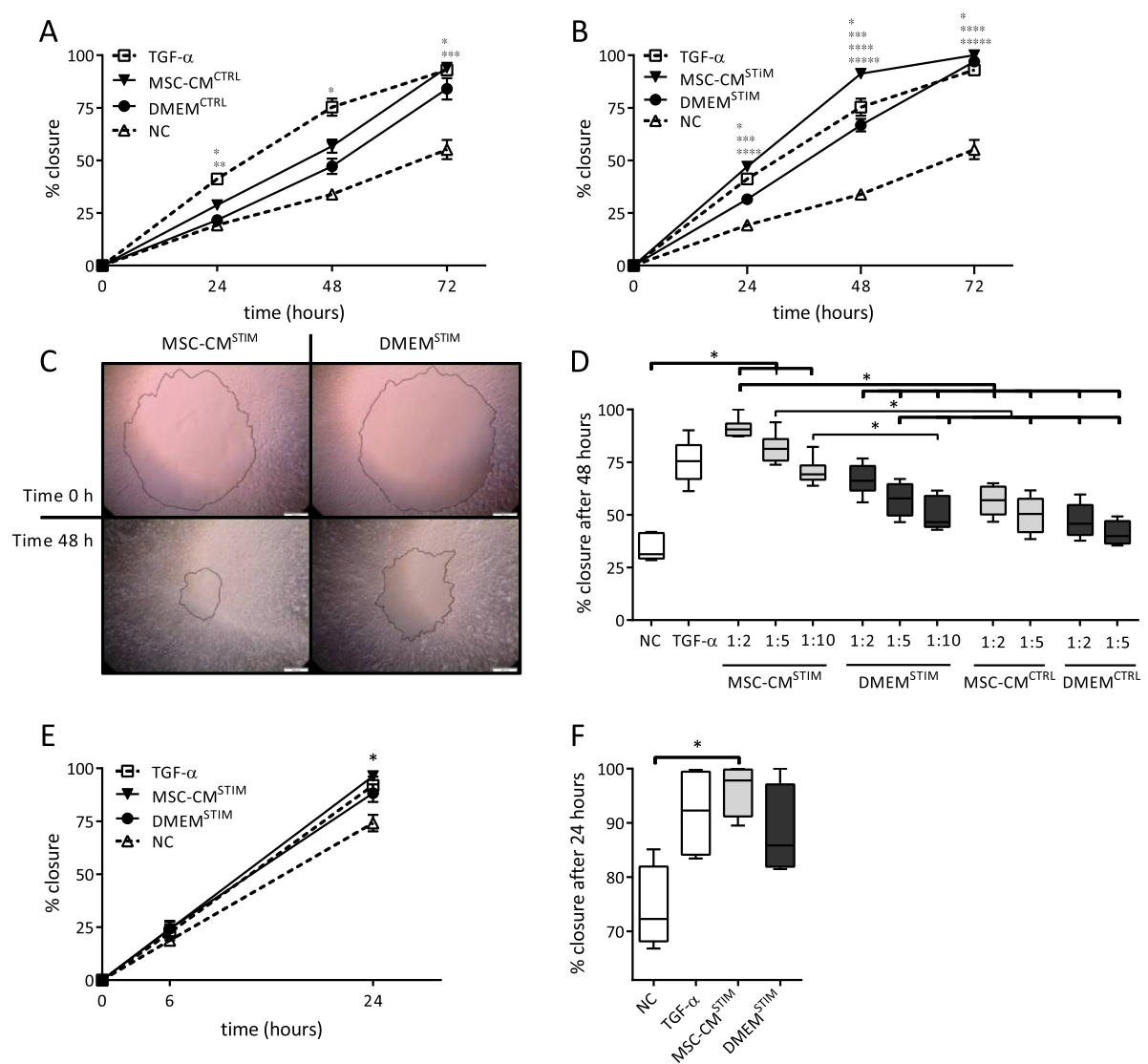

Fig. 2 MSC-CM increases wound closure. a, b: NCl-H292 cells were injured by making a circular wound with a diameter of 3 mm, and subsequently incubated with MSC-CM ${ }^{C T R L}$, MSC-CM ${ }^{\text {STM }}$, DMEM ${ }^{\text {CTRL }}$ and DMEM ${ }^{\text {STIM }}$, and a negative control (NC, RPMl only) and positive control (RPMI supplemented with TGF- $a 20 \mathrm{ng} / \mathrm{ml})$. The wound size was measured at 0, 24, 48 and $72 \mathrm{~h}$ after wounding. MSC-CM ${ }^{\text {STIM }}$ significantly increased wound closure. The effect of MSC-CM ${ }^{\text {STM M }}$ was dose-dependent. Error bars represent standard error of the mean (SEM). $n=4-6 ;\left(^{*}\right) p<0.05$ TGF-a compared to NC and $\left(^{* *}\right)$

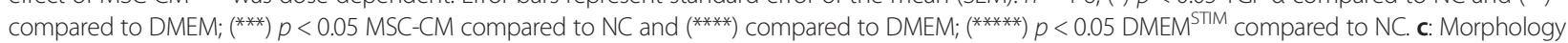
of the closure of the wound: photos in the upper panel are taken at $\mathrm{t}=0 \mathrm{~h}$, the lower panel shows the same wounds photographed $48 \mathrm{~h}$ later. The two photos on the left side are obtained from MSC-CM ${ }^{\text {STM }}$ stimulated cells, whereas photos at the right represent its control, DMEM ${ }^{\text {STM }}$. d: Dose response. Box and whiskers represent median, interquartile range and minimum and maximum. $n=4-6 ;\left(^{*}\right) p<0.05$. e: Wound closure in ALI-PBEC measured at 6 and $24 \mathrm{~h}$ (at $48 \mathrm{~h}$ all wounds were closed). At $24 \mathrm{~h}, \mathrm{MSC}-\mathrm{CM}^{\text {STIM }}$ significantly enhanced wound healing compared to the NC, but no

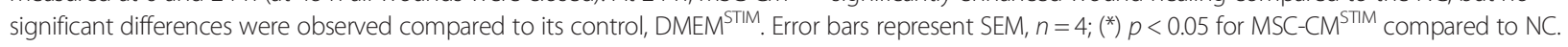
f. Wound closure in ALI-PBEC at $24 \mathrm{~h}$. Box and whiskers represent median, interquartile range and minimum and maximum, for $n=4$ as in Fig. $2 f$; $\left({ }^{*}\right) p<0.05$

Next, the involvement of two upstream receptors, c-Met (HGF-receptor) and Epidermal Growth Factor Receptor (EGFR), in ERK1/2 phosphorylation by MSC-CM ${ }^{\text {STIM }}$ was explored using a tyrosine kinase inhibitor to block c-Met and EGFR, or neutralizing anti-EGFR antibodies. Control experiments showed that ligands for both c-Met (HGF) and EGFR (TGF- $\alpha$ ) are potent activators of ERK1/2, and that the respective inhibitors block this activation effectively and specifically (data not shown). At 15 min, phosphorylation of ERK1/2 by MSC-CM ${ }^{\text {STIM }}$ was inhibited by the EGFR inhibitor (AG) and EGFR neutralizing antibodies ( $\alpha$ EGFR) (Fig. 4a-d), but was not affected by the cMet inhibitor (PF) (Fig. 4a, b). This shows that although both EGFR and c-Met are potent activators of ERK1/2, the increase in ERK1/2 phosphorylation as observed upon stimulation with MSC-CM ${ }^{\mathrm{STIM}}$ is mainly mediated via the EGFR pathway.

Besides direct EGFR-dependent activation of ERK1/2 by constituents of the MSC-CM, it is also known that airway epithelial cells promote wound healing in an autocrine manner, via transactivation of EGFR. In this process, matrix metalloproteinases, predominantly TACE/ADAM17, mediate the shedding of cell surface-bound EGFR ligands [34]. These ligands in turn activate ERK1/2 via EGFR. Addition of a TACE/ADAM17 inhibitor (TAPI-1) decreased ERK1/2 phosphorylation induced by MSC-CM ${ }^{\text {STIM }}$ (Fig. 4c, d). This suggests that EGFR transactivation through TACE/ADAM17 contributes to ERK1/2 phosphorylation in NCI-H292 monolayers, in addition to direct effects of MSC-CM ${ }^{\text {STIM }}$. 
A
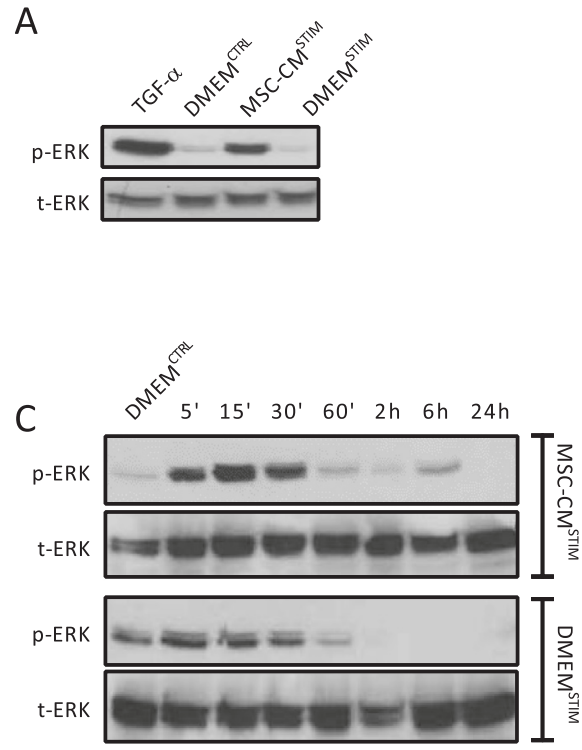

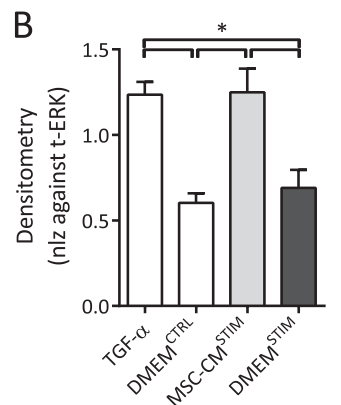

D

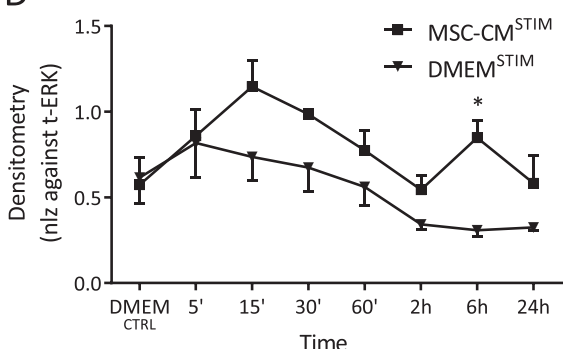

Fig. 3 MSC-CM ${ }^{\text {STIM }}$ increases ERK1/2 phosphorylation. NCl-H292 cells were incubated with MSC-CM ${ }^{\text {STIM }}$, DMEM ${ }^{\text {STIM }}$, DMEM ${ }^{C T R L}$ or TGF-a 20 ng/ml (pos ctrl). ERK1/2 phosphorylation and total ERK was determined in cell lysates using Western blot. a: After 15 min incubation time MSC-CM ${ }^{\text {TTIM }}$ increased ERK1/2 phosphorylation compared to its control. b: Densitometry for Fig. $3 a$. Error bars represent SEM, $n=6$; $(*) p<0.05$. c: Time course experiment, demonstrating that the effect of MSC-CM ${ }^{\text {STIM }}$ was most prominent up to 30 min, but could still be observed up to 6 h. DMEM ${ }^{C T R L}$ was obtained at $15 \mathrm{~min}$. d: Densitometry for Fig. 3c. Error bars represent SEM, $n=4-5 ;\left(^{*}\right) p<0.05$

This raised the question whether MSC-CM ${ }^{\text {STIM }}$ could induce EGFR ligand expression in airway epithelial cells. To investigate this, NCI-H292 were incubated with MSC$\mathrm{CM}^{\text {STIM }}$ and gene expression of several EGFR ligands was assessed. A significant increase of mRNA expression of both AREG and HBEGF was observed upon stimulation with MSC-CM ${ }^{\text {STIM }}$ compared to its control (Fig. 4e).

Enhanced ERK1/2 activation promotes in part cell proliferation by increasing expression of Cyclin D1 (CCDN1) [35], a cell cycle regulator. In line with $\mathrm{MSC}-\mathrm{CM}^{\mathrm{STIM}}$ induced ERK1/2 phosphorylation, the mRNA expression of $C C D N 1$ was significantly higher compared to its control, suggesting an increase in cell proliferation (Fig. 4f).

\section{Blocking of the EGFR reduces the stimulatory effect of MSC-CM ${ }^{\text {STIM }}$ on wound healing} In NCI-H292 monolayers, stimulation with MSC-CM ${ }^{\text {STIM }}$ resulted in increased ERK1/2 phosphorylation, and this process appeared to be predominantly regulated via EGFR signaling. To assess if this observation could be translated into a functional effect, wound healing experiments were repeated using the before mentioned tyrosine kinase inhibitors. To limit toxic side effects after prolonged exposure to high doses of AG, we adjusted the concentration of AG to $0.2 \mu \mathrm{M}$ based on dose-response experiments; for the c-Met inhibitor PF a concentration of $0.05 \mu \mathrm{M}$ sufficed (data not shown).

The EGFR ligand TGF- $\alpha$ and the c-Met ligand HGF both significantly enhanced wound healing in NCI-H292 monolayers, indicating that both their corresponding receptors could be involved in MSC-mediated wound repair. Inhibition of EGFR as well as of c-Met blocked the effect of TGF- $\alpha$ and HGF, respectively (Fig. 5a). In the presence of the EGFR inhibitor the effect of MSC$\mathrm{CM}^{\text {STIM }}$ on wound closure was significantly reduced to a level similar to that observed in the negative control. Blocking of the HGF receptor c-Met alone had no effect on wound closure induced by MSC-CM ${ }^{\text {STIM }}$ (Fig. 5b).

These data indicate that signaling through EGFR is the predominant pathway by which MSC-CM ${ }^{\text {STIM }}$ increased wound healing in NCI-H292 epithelial cells.

\section{Discussion}

This study shows for the first time that stimulation of MSCs with pro-inflammatory cytokines improves their capacity to enhance airway epithelial repair in an in vitro repair model using the airway epithelial cell line NCI$\mathrm{H} 292$. We show that conditioned medium from human bone marrow-derived MSCs increases wound healing in airway epithelial cells and that this effect is significantly enhanced when the MSCs are treated with a mixture of pro-inflammatory cytokines, i.e. TNF- $\alpha$ and IL- $1 \beta$. These cytokines increased the mRNA expression of the growth factors FGF2, HBEGF, HGF, and of IL6 in MSCs. We provide evidence for the possible involvement of the following mechanisms in this enhancing effect of MSC$\mathrm{CM}^{\text {STIM }}$ on wound repair (Fig. 6): first, MSC-CM ${ }^{\text {STIM }}$ directly activated the MAP kinase ERK1/2 via EGFR, 
A

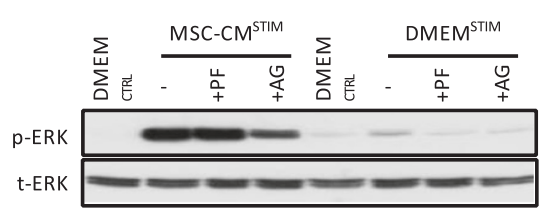

C

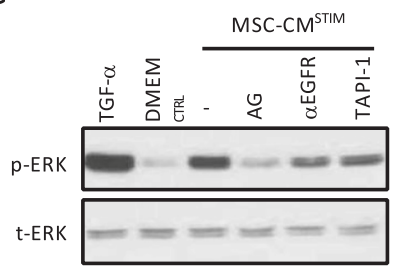

B

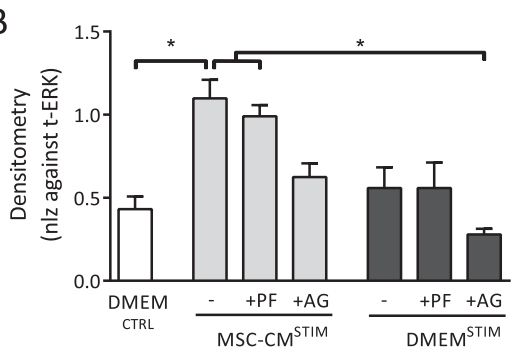

D

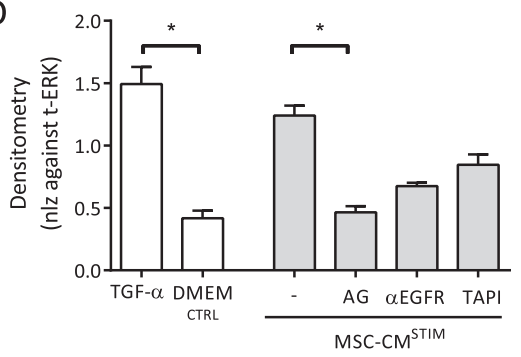

$\mathrm{F}$
$\mathrm{E}$

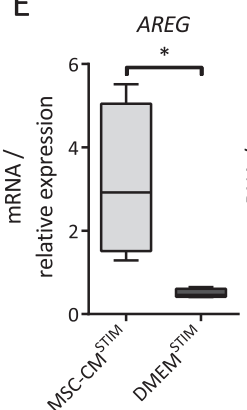

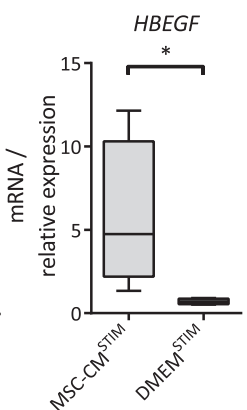

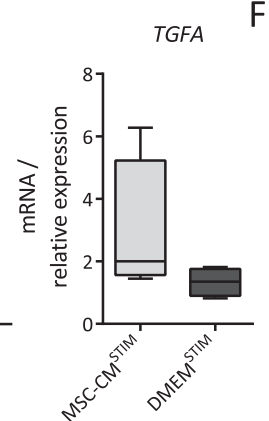

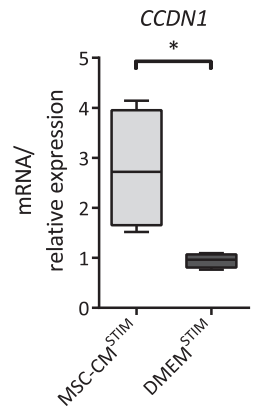

Fig. 4 MSC-CM ${ }^{\text {STIM }}$ induced ERK1/2 phosphorylation is mediated via (trans)activation of EGFR. a: 1 h pre-incubation of NCl-H292 with $0.05 \mu M$ PF04217903 and/or 10 MM AG1478, followed by 15 min stimulation with MSC-CM ${ }^{\text {STIM }}$ or DMEM ${ }^{\text {STIM }}$, or DMEM ${ }^{\text {CTRL }}$ showed that inhibition of EGFR decreased ERK1/2 phosphorylation as determined using Western blot. b: Densitometry for Fig. 4a. Error bars represent SEM, $n=5 ;(*) p<0.05$. c: $1 \mathrm{~h}$ pre-incubation with $2 \mu \mathrm{g} / \mathrm{ml}$ neutralizing anti-EGFR antibodies and $10 \mu \mathrm{M}$ TAPI-1 followed by incubation with MSC-CM ${ }^{\text {STIM }}$ during 15 min showed that these agents decreased ERK1/2 phosphorylation. d: Densitometry for Fig. 4C. Error bars represent SEM, $n=3 ;\left(^{*}\right) p<0.05$. e: NCI-H292 cells were incubated with MSC-CM ${ }^{\text {STIM }}$ or DMEM ${ }^{\text {STIM }}$ and harvested after $9 \mathrm{~h}$ for mRNA analysis. mRNA expression of the EGFR ligands AREG, HBEGF and TGFA was determined by qPCR. MSC-CM ${ }^{\text {STIM }}$ significantly increased the expression of AREG and HBEGF. Expression of TGFA increased but this was not significant. $\mathbf{f}$ : mRNA expression of the proliferation marker CCDN1 was significantly increased. Values were normalized against RPL13A and ATP5B reference genes. Box and whiskers represent median, interquartile range and minimum and maximum. $n=4 ;\left({ }^{*}\right) p<0.05$

resulting in wound healing. Second, MSC-CM${ }^{\text {STIM }}$ caused ADAM-mediated transactivation of EGFR, further contributing to wound healing. Third, MSC-CM ${ }^{\text {STIM }}$ increased mRNA expression of EGFR ligands AREG and HBEGF in NCI-H292 airway epithelial cells.

Previous studies show that MSCs contribute to epithelial repair in wound healing models in vivo as well as in vitro $[8,17,36]$, and that pro-inflammatory cytokines can attract MSCs to sites of inflammation [37]. Within such an inflammatory environment, MSCs display an anti-inflammatory phenotype that is characterized by an increased expression of IL6 [38]. In line with this observation, we noted increased expression of IL6 in MSCs stimulated with TNF- $\alpha$ and IL-1 $\beta$, suggesting anticipated response to these pro-inflammatory stimuli. Besides increased mRNA expression of IL6, we observed increased
mRNA expression of several growth factors in TNF- $\alpha$ / IL-1 $\beta$ stimulated MSCs, suggesting that the regenerative potential of these MSCs is enhanced. The increased mRNA expression of several EGFR ligands was not accompanied by increased levels of these ligands as detected by ELISA (data not shown). This may be explained by limitations in the sensitivity of the ELISAs, rapid binding of secreted growth factors to their cellular receptors, and/or by the fact that the observed effects are not explained by detectable levels of single EGFR ligands, but by synergisms between various released mediators. In line with our observations, previous reports also demonstrated that stimulation with pro-inflammatory cytokines induces growth factor expression by MSCs $[20,39,40]$. However, to our knowledge this is the first study demonstrating that pro-inflammatory cytokine 

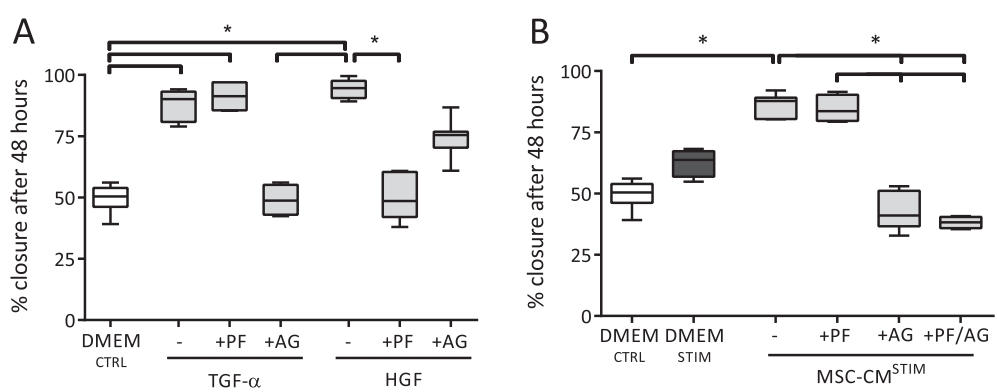

Fig. 5 Blocking of EGFR reduces the stimulatory effect of MSC-CM ${ }^{\text {STIM }}$ on wound closure. a: NCl-H292 wounded cell layers were stimulated with MSC$\mathrm{CM}^{\text {STIM }}$ or DMEM ${ }^{\text {STM }}$, DMEM ${ }^{\text {CTRL }}$, or DMEM supplemented with TGF-a $20 \mathrm{ng} / \mathrm{ml}$ or HGF $20 \mathrm{ng} / \mathrm{ml}$ (positive controls). Inhibitors of EGFR ( $0.2 \mu \mathrm{M}$

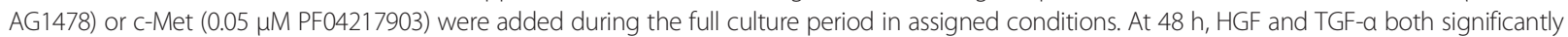
enhanced wound healing in $\mathrm{NCl}-\mathrm{H} 292$ cells, which was averted to a level comparable to the negative control by their respective inhibitors. $\mathbf{b}$ : In the presence of the EGFR inhibitor, the wound healing capacity of MSC-CM ${ }^{\text {STIM }}$ decreased to values below those observed in the negative control as determined after $48 \mathrm{~h}$. Inhibition of $\mathrm{c}-$ Met alone had no effect on wound healing induced by MSC-CM ${ }^{\mathrm{STM} M}$. Box and whiskers represent median, interquartile range and minimum and maximum. $n=4-7 ;\left(^{*}\right) p<0.05$

stimulation of MSCs induces wound healing in airway epithelial cells, and our data indicate that this may involve the action of growth factors. Together, this suggests that the capacity of MSCs to enhance wound repair may be increased upon recruitment to areas of inflammation where they are exposed to pro-inflammatory cytokines [25]. This is relevant for a disease such as COPD, where both inflammation and tissue damage are present.

Amongst the growth factors induced in TNF- $\alpha / \mathrm{IL}-1 \beta-$ stimulated MSCs, EGFR ligands and HGF are involved

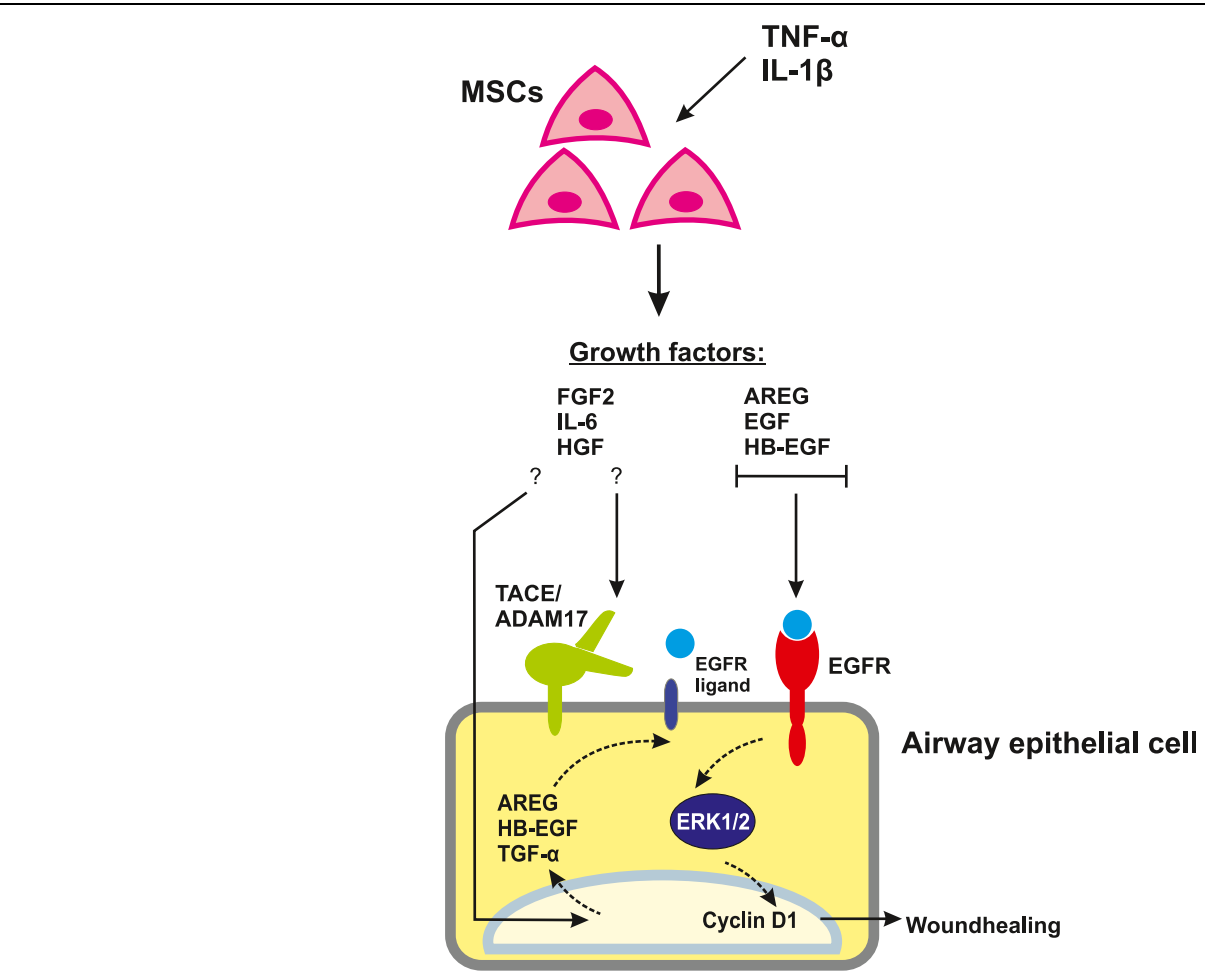

Fig. 6 Proposed model of enhanced wound closure in airway epithelial cells by MSC-CM ${ }^{\text {STIM }}$. In MSCS, exposure to TNF-a and IL-1 $\beta$ increases the mRNA expression of various growth factors. Conditioned medium from these MSCs contributes to wound healing of airway epithelial cells via three mechanisms: direct activation of EGFR; activation of matrix metalloproteases which results in shedding of membrane bound EGFR ligands; induction of mRNA expression of EGFR ligands by the airway epithelium. Activation of the downstream MAP kinase ERK1/2, which is known as a regulator of cell proliferation (a.o. assessed by increased Cyclin D1) and differentiation, subsequently results in increased wound healing 
in airway epithelial wound repair [41-44]. By using inhibitors for EGFR and c-Met, we show that the effect of MSC-CM ${ }^{\text {STIM }}$ on both ERK1/2 activation as well as on wound healing was mediated by EGFR activation, without an apparent effect of c-Met inhibition. As it has been shown that HGF can promote airway epithelial wound repair [43,44], we speculate that in our model HGF has a more subtle contribution to wound healing that is masked by the major role of EGFR signaling in airway epithelial repair. This is supported by a study from Curley et al., who showed that the addition of HGF-neutralizing antibodies to MSC-CM in a scratch wound assay using A549 alveolar epithelial cells did not affect wound repair [45]. Besides HGF and EGFR ligands, other MSC-CM ${ }^{\text {STIM }}$ constituents can contribute to wound healing. One example of a possibly involved MSC-derived mediator is IL-6, which was previously found to contribute to MSC-mediated epithelial wound repair $[36,46]$. Although in our model blocking of EGFR fully inhibited the stimulatory effect of MSC-CM ${ }^{\text {STIM }}$, we cannot exclude a contribution of MSC-derived IL-6.

In addition to direct EGFR activation, we observe that MSC-CM ${ }^{\text {STIM }}$ activates ERK1/2 via transactivation of EGFR. EGFR-transactivation results from activation of Gprotein coupled receptors (GPCRs) that activate proteases of the ADAM family, such as TACE/ADAM17. These proteases cleave cell surface-bound EGFR ligands, resulting in autocrine EGFR activation [34]. Numerous factors are able to activate GPCRs, and our study focussed on the role of a modest selection of growth factors and chemokines. It was beyond the scope of this study to investigate other ligands potentially released by MSCs, but this will be an interesting point for future investigations.

In our model, we have used the airway epithelial cell line NCI-H292. This cell line has been shown to respond in a similar fashion as primary epithelial cells of the lung and is frequently used to study effects mediated by the EGFR axis [47-50]. The use of a cell line limits translation to the in vivo situation, where in addition to the epithelium also immune and endothelial cells interact in the process of wound repair. The benefit on the other hand is that it allows for detailed investigation of MSC$\mathrm{CM}^{\text {STIM }}$ effects on the ERK1/2 signaling pathway as well as on cell proliferation.

The circular wounds used in this study are relatively large and NCI-H292 cells require cell proliferation in order to close this type of wound as we have shown previously [32]. This adds information about effects on cell proliferation that cannot be obtained when using primary bronchial epithelial cells (PBEC) using wounds of a similar size, as migratory mechanisms appear to suffice for the closure of this type of wounds [51]. For the same reasons, the wound repair model also provides additional information to the more commonly used scratch wound assays, as these scratch wounds close quickly, and primarily via cell migratory mechanisms [17]. Using ALI-PBEC, we observed effects of MSC-CM ${ }^{\text {STIM }}$ on epithelial wound healing, but unlike the observation in NCI-H292, this effect was not significantly different compared to control medium $\left(\mathrm{DMEM}^{\mathrm{STIM}}\right)$. We speculate that higher intrinsic rate of wound closure in ALI-PBEC and donor variability limited the experimental window to observe beneficial effects of MSC-CM. Besides, differences in intrinsic wound healing characteristics (e.g. primarily via migration rather than proliferation in ALI-PBEC), as well as direct effects of TNF- $\alpha$ and IL- $1 \beta$ on migratory processes might further explain differences in effects of MSC-CM ${ }^{\text {STIM }}$ on ALI-PBEC versus NCI-H292.

Our data provide evidence for the concept of a cell-based therapy with cells that specifically interact with an inflammatory environment to enhance their beneficial properties. Safety concerns regarding tumorigenesis or fibrosis might arise when using cell-based therapies, but based on current data obtained from clinical trials the use of MSCs in patients is considered to be safe [52]. Moreover, it has been shown in multiple studies that MSCs can induce apoptosis of cancer (but not healthy) cells via tumor necrosis factorrelated apoptosis-inducing ligand [53, 54].

MSCs are currently considered as treatment for COPD and the first patient safety and feasibility study has recently been published [55]. Interestingly, the results from the present study suggest that exposure of MSCs to pro-inflammatory cytokines increases their ability to repair damaged tissue. This may imply that MSCs are more effective at sites of inflammation and that in vitro stimulation of MSCs with cytokines before infusion in patients may potentially result in a larger therapeutic effect. Future investigations should be directed at further exploring the mechanisms involved in the enhancing effect of MSCs on epithelial wound healing, using e.g. primary airway and alveolar epithelial cells, preferably using co-cultures of MSCs with epithelial cells.

\section{Conclusions}

We have found that MSC conditioned medium obtained from MSCs stimulated with a mixture of cytokines potently enhances wound repair in injured airway epithelial cells. This effect is predominantly mediated by (trans)activation of EGFR and subsequent activation of the ERK1/2 signaling cascade. This observation implies that in areas of tissue damage where inflammatory mediators are present (such as in the lungs of COPD patients), MSCs may display increased regenerative properties via the secretion of growth factors. This supports the concept that MSCs are a promising candidate for cell-based therapy in inflammatory lung diseases such as COPD. 


\section{Abbreviations}

ADAM: a disintegrin and metalloprotease; ALI: air liquid interface; AREG: amphiregulin; BSA: bovine serum albumin; BPE: bovine pituitary extract; CCDN1: cyclin D1; CM: conditioned medium; COPD: chronic obstructive pulmonary disease; EGF(R): epidermal growth factor (receptor); ERK: extracellular signal-regulated kinase; FGF2: fibroblast growth factor 2; GPCR: G-protein coupled receptor; HB-EGF: heparin binding EGF-like growth factor; HC: hydrocortisone; HGF: hepatocyte growth factor; IL-1B: interleukin-1 $\beta$; IL-6: interleukin-6; MAPK: mitogen activated protein kinase; MMP: matrix metalloproteinase; MSC: mesenchymal stromal cell; MSC-CM ${ }^{C T R L}$ : conditioned medium obtained from unstimulated MSCS; MSC-CM ${ }^{\text {STM }}$ : conditioned medium obtained from TNF- $\alpha /$ LL-1 $\beta$ stimulated MSCs; PBEC: primary bronchial epithelial cells; PDGFA: platelet derived growth factor a; RA: retinoic acid; SEM: standard error of the mean; TACE: TNF-a converting enzyme; TGF-a: transforming growth factor-a; TNF-a: tumour necrosis factor-a; VEGF(R): vascular endothelial growth factor (receptor).

\section{Competing interests}

The authors declare that they have no competing interests.

\section{Authors' contributions}

WB coordinated the study, contributed to the study design, carried out the laboratory procedures and drafted the manuscript and figures. GDA contributed to the study design, experiments, and interpretation of the data and helped drafting the manuscript and figures. YME was responsible for the PCR experiments. JO, HR and JS contributed to the study design, interpretation of the data and manuscript revision. CT contributed to the coordination of the study and to the interpretation of the data. PSH designed the study, contributed to interpretation of the data and writing and editing of the manuscript. All authors read and approved the final manuscript.

\section{Acknowledgements}

The authors thank Renate Verhoosel from Leiden University Medical Center (LUMC) for technical assistance and Suzanne Zuyderduyn (LUMC) for her contribution to the initial phase of the study.

\section{Author details}

'Department of Pulmonology, Leiden University Medical Center, Albinusdreef 2, 2333 ZA Leiden, The Netherlands. ${ }^{2}$ Department of Clinical Pharmacy and Toxicology, Leiden University Medical Center, Leiden, The Netherlands. ${ }^{3}$ Department of Immunohaematology and Blood Transfusion, Leiden University Medical Center, Leiden, The Netherlands.

Received: 19 January 2015 Accepted: 15 December 2015 Published online: 11 January 2016

\section{References}

1. Barnes PJ. Chronic obstructive pulmonary disease. N Engl J Med. 2000;343:269-80

2. Brusselle GG, Joos GF, Bracke KR. New insights into the immunology of chronic obstructive pulmonary disease. Lancet. 2011;378:1015-26.

3. Rabe KF, Hurd S, Anzueto A, Barnes PJ, Buist SA, Calverley P, et al. Global strategy for the diagnosis, management, and prevention of chronic obstructive pulmonary disease: GOLD executive summary. Am J Respir Crit Care Med. 2007;176:532-55.

4. Barnes PJ. New anti-inflammatory targets for chronic obstructive pulmonary disease. Nat Rev Drug Discov. 2013;12:543-59.

5. Dominici M, Le BK, Mueller I, Slaper-Cortenbach I, Marini F, Krause D, et al. Minimal criteria for defining multipotent mesenchymal stromal cells. The International Society for Cellular Therapy position statement. Cytotherapy. 2006:8:315-7.

6. Meirelles LS, Fontes AM, Covas DT, Caplan Al. Mechanisms involved in the therapeutic properties of mesenchymal stem cells. Cytokine Growth Factor Rev. 2009;20:419-27.

7. Nauta AJ, Fibbe WE. Immunomodulatory properties of mesenchymal stromal cells. Blood. 2007;110:3499-506.

8. Guan XJ, Song L, Han FF, Cui ZL, Chen X, Guo XJ, et al. Mesenchymal stem cells protect cigarette smoke-damaged lung and pulmonary function partly via VEGF-VEGF receptors. J Cell Biochem. 2013;114:323-35.
9. Huh JW, Kim SY, Lee JH, Lee JS, Van TQ, Kim M, et al. Bone marrow cells repair cigarette smoke-induced emphysema in rats. Am J Physiol Lung Cell Mol Physiol. 2011;301:L255-66.

10. Katsha AM, Ohkouchi S, Xin H, Kanehira M, Sun R, Nukiwa T, et al. Paracrine factors of multipotent stromal cells ameliorate lung injury in an elastaseinduced emphysema model. Mol Ther. 2011;19:196-203.

11. Kim JS, McKinnis VS, Nawrocki A, White SR. Stimulation of migration and wound repair of guinea-pig airway epithelial cells in response to epidermal growth factor. Am J Respir Cell Mol Biol. 1998;18:66-74.

12. Panos RJ, Patel R, Bak PM. Intratracheal administration of hepatocyte growth factor/scatter factor stimulates rat alveolar type II cell proliferation in vivo. Am J Respir Cell Mol Biol. 1996;15:574-81.

13. Crosby LM, Waters CM. Epithelial repair mechanisms in the lung. Am J Physiol Lung Cell Mol Physiol. 2010;298:L715-31.

14. Ryan RM, Mineo-Kuhn MM, Kramer CM, Finkelstein JN. Growth factors alter neonatal type II alveolar epithelial cell proliferation. Am J Physiol. 1994;266:L17-22.

15. Leslie CC, McCormick-Shannon K, Shannon JM, Garrick B, Damm D, Abraham JA, et al. Heparin-binding EGF-like growth factor is a mitogen for rat alveolar type II cells. Am J Respir Cell Mol Biol. 1997;16:379-87.

16. Chang L, Karin M. Mammalian MAP kinase signalling cascades. Nature. 2001;410:37-40.

17. Akram KM, Samad S, Spiteri MA, Forsyth NR. Mesenchymal stem cells promote alveolar epithelial cell wound repair in vitro through distinct migratory and paracrine mechanisms. Respir Res. 2013;14:9.

18. Chamberlain G, Fox J, Ashton B, Middleton J. Concise review: mesenchymal stem cells: their phenotype, differentiation capacity, immunological features, and potential for homing. Stem Cells. 2007;25:2739-49.

19. Karp JM, Leng Teo GS. Mesenchymal stem cell homing: the devil is in the details. Cell Stem Cell. 2009:4:206-16.

20. Crisostomo PR, Wang Y, Markel TA, Wang M, Lahm T, Meldrum DR. Human mesenchymal stem cells stimulated by TNF-alpha, LPS, or hypoxia produce growth factors by an NF kappa B- but not JNK-dependent mechanism. Am J Physiol Cell Physiol. 2008;294:C675-82.

21. Miettinen JA, Pietila M, Salonen RJ, Ohlmeier S, Ylitalo K, Huikuri HV, et al. Tumor necrosis factor alpha promotes the expression of immunosuppressive proteins and enhances the cell growth in a human bone marrow-derived stem cell culture. Exp Cell Res. 2011;317:791-801.

22. Ren G, Zhang L, Zhao X, Xu G, Zhang Y, Roberts Al, et al. Mesenchymal stem cell-mediated immunosuppression occurs via concerted action of chemokines and nitric oxide. Cell Stem Cell. 2008;2:141-50.

23. Ryan JM, Barry F, Murphy JM, Mahon BP. Interferon-gamma does not break, but promotes the immunosuppressive capacity of adult human mesenchymal stem cells. Clin Exp Immunol. 2007;149:353-63.

24. Ren G, Zhao X, Zhang L, Zhang J, L'Huillier A, Ling W, et al. Inflammatory cytokine-induced intercellular adhesion molecule-1 and vascular cell adhesion molecule-1 in mesenchymal stem cells are critical for immunosuppression. J Immunol. 2010;184:2321-8.

25. Heo SC, Jeon ES, Lee $H$, Kim HS, Kim MB, Kim JH. Tumor necrosis factor-alpha-activated human adipose tissue-derived mesenchymal stem cells accelerate cutaneous wound healing through paracrine mechanisms. J Invest Dermatol. 2011;131:1559-67.

26. Keatings VM, Collins PD, Scott DM, Barnes PJ. Differences in interleukin-8 and tumor necrosis factor-alpha in induced sputum from patients with chronic obstructive pulmonary disease or asthma. Am J Respir Crit Care Med. 1996;153:530-4.

27. Lappalainen U, Whitsett JA, Wert SE, Tichelaar JW, Bry K. Interleukin-1beta causes pulmonary inflammation, emphysema, and airway remodeling in the adult murine lung. Am J Respir Cell Mol Biol. 2005;32:311-8.

28. Lucey EC, Keane J, Kuang PP, Snider GL, Goldstein RH. Severity of elastaseinduced emphysema is decreased in tumor necrosis factor-alpha and interleukin-1 beta receptor-deficient mice. Lab Invest. 2002;82:79-85.

29. Pauwels NS, Bracke KR, Dupont LL, Van Pottelberge GR, Provoost S, Vanden Berghe T, et al. Role of IL-1alpha and the Nlrp3/caspase-1/L-1beta axis in cigarette smoke-induced pulmonary inflammation and COPD. Eur Respir J. 2011;38:1019-28.

30. Amatngalim GD, Van WY, de Mooij-Eijk Y, Verhoosel RM, Harder J, Lekkerkerker AN, et al. Basal cells contribute to innate immunity of the airway epithelium through production of the antimicrobial protein RNase 7. J Immunol. 2015;194:3340-50.

31. Duijvestein M, Vos AC, Roelofs $H$, Wildenberg ME, Wendrich BB, Verspaget $\mathrm{HW}$, et al. Autologous bone marrow-derived mesenchymal stromal cell 
treatment for refractory luminal Crohn's disease: results of a phase I study. Gut. 2010;59:1662-9.

32. Aarbiou J, Verhoosel RM, Van WS, de Boer WI, van Krieken JH, Litvinov SV, et al. Neutrophil defensins enhance lung epithelial wound closure and mucin gene expression in vitro. Am J Respir Cell Mol Biol. 2004;30:193-201.

33. Aarbiou J, Ertmann M, Van WS, Van NP, Rook D, Rabe KF, et al. Human neutrophil defensins induce lung epithelial cell proliferation in vitro. J Leukoc Biol. 2002;72:167-74.

34. Burgel PR, Nadel JA. Epidermal growth factor receptor-mediated innate immune responses and their roles in airway diseases. Eur Respir J. 2008;32:1068-81.

35. Treinies I, Paterson HF, Hooper S, Wilson R, Marshall CJ. Activated MEK stimulates expression of AP-1 components independently of phosphatidylinositol 3-kinase (PI3-kinase) but requires a PI3-kinase signal To stimulate DNA synthesis. Mol Cell Biol. 1999;19:321-9.

36. Yew TL, Hung YT, Li HY, Chen HW, Chen LL, Tsai KS, et al. Enhancement of wound healing by human multipotent stromal cell conditioned medium: the paracrine factors and p38 MAPK activation. Cell Transplant. 2011;20:693-706.

37. Ries C, Egea V, Karow M, Kolb H, Jochum M, Neth P. MMP-2, MT1-MMP, and TIMP-2 are essential for the invasive capacity of human mesenchymal stem cells: differential regulation by inflammatory cytokines. Blood. 2007;109:4055-63.

38. Bernardo ME, Fibbe WE. Mesenchymal stromal cells: sensors and switchers of inflammation. Cell Stem Cell. 2013;13:392-402.

39. Wang M, Crisostomo PR, Herring C, Meldrum KK, Meldrum DR. Human progenitor cells from bone marrow or adipose tissue produce VEGF, HGF, and IGF-I in response to TNF by a p38 MAPK-dependent mechanism. Am J Physiol Regul Integr Comp Physiol. 2006;291:R880-4.

40. Zhang A, Wang Y, Ye Z, Xie H, Zhou L, Zheng S. Mechanism of TNF-alphainduced migration and hepatocyte growth factor production in human mesenchymal stem cells. J Cell Biochem. 2010;111:469-75.

41. Koff JL, Shao MX, Kim S, Ueki IF, Nadel JA. Pseudomonas lipopolysaccharide accelerates wound repair via activation of a novel epithelial cell signaling cascade. J Immunol. 2006;177:8693-700

42. Puddicombe SM, Polosa R, Richter A, Krishna MT, Howarth PH, Holgate ST, et al. Involvement of the epidermal growth factor receptor in epithelial repair in asthma. FASEB J. 2000;14:1362-74.

43. Ohmichi H, Matsumoto K, Nakamura T. In vivo mitogenic action of HGF on lung epithelial cells: pulmotrophic role in lung regeneration. Am J Physiol. 1996;270:L1031-9.

44. Zahm JM, Debordeaux C, Raby B, Klossek JM, Bonnet N, Puchelle E. Motogenic effect of recombinant HGF on airway epithelial cells during the in vitro wound repair of the respiratory epithelium. J Cell Physiol. 2000;185:447-53.

45. Curley GF, Hayes M, Ansari B, Shaw G, Ryan A, Barry F, et al. Mesenchymal stem cells enhance recovery and repair following ventilator-induced lung injury in the rat. Thorax. 2012;67:496-501.

46. Wang WC, Kuo CY, Tzang BS, Chen HM, Kao SH. IL-6 augmented motility of airway epithelial cell BEAS-2B via Akt/GSK-3beta signaling pathway. J Cell Biochem. 2012;113:3567-75.

47. Newland N, Richter A. Agents associated with lung inflammation induce similar responses in NCI-H292 lung epithelial cells. Toxicol In Vitro. 2008;22:1782-8.

48. Takeyama K, Dabbagh K, Lee HM, Agusti C, Lausier JA, Ueki IF, et al. Epidermal growth factor system regulates mucin production in airways. Proc Natl Acad Sci U S A. 1999;96:3081-6.

49. Zhang $Y$, Zhu M, Yang Z, Pan X, Jiang Y, Sun $C$, et al. The human Cathelicidin LL-37 induces MUC5AC mucin production by airway epithelial cells via TACE-TGF-alpha-EGFR pathway. Exp Lung Res. 2014;40:333-42.

50. Shao MX, Nakanaga T, Nadel JA. Cigarette smoke induces MUC5AC mucin overproduction via tumor necrosis factor-alpha-converting enzyme in human airway epithelial (NCl-H292) cells. Am J Physiol Lung Cell Mol Physiol. 2004;287:L420-7.

51. Luppi F, Aarbiou J, Van WS, Rahman I, de Boer WI, Rabe KF, et al. Effects of cigarette smoke condensate on proliferation and wound closure of bronchial epithelial cells in vitro: role of glutathione. Respir Res. 2005;6:140,

52. Prockop DJ, Brenner M, Fibbe WE, Horwitz E, Le BK, Phinney DG, et al. Defining the risks of mesenchymal stromal cell therapy. Cytotherapy. 2010;12:576-8

53. Sage EK, Kolluri KK, McNulty K, Lourenco SS, Kalber TL, Ordidge KL, et al. Systemic but not topical TRAlL-expressing mesenchymal stem cells reduce tumour growth in malignant mesothelioma. Thorax. 2014;69:638-47.
54. Mohr A, Albarenque SM, Deedigan L, Yu R, Reidy M, Fulda S, et al. Targeting of XIAP combined with systemic mesenchymal stem cell-mediated delivery of sTRAlL ligand inhibits metastatic growth of pancreatic carcinoma cells. Stem Cells. 2010;28:2109-20.

55. Weiss DJ, Casaburi R, Flannery R, LeRoux-Williams M, Tashkin DP. A placebocontrolled, randomized trial of mesenchymal stem cells in COPD. Chest. 2013;143:1590-8.

\section{Submit your next manuscript to BioMed Central and we will help you at every step:}

- We accept pre-submission inquiries

- Our selector tool helps you to find the most relevant journal

- We provide round the clock customer support

- Convenient online submission

- Thorough peer review

- Inclusion in PubMed and all major indexing services

- Maximum visibility for your research

Submit your manuscript at www.biomedcentral.com/submit
() Biomed Central 